\title{
The Replication of the System of Conductive Education in the United States
}

\author{
Andrea Benyovszky*
}

\begin{abstract}
During the 1980s, the methodology of Hungarian-created conductive education began its innovation in becoming an international model for working with individuals with physical disabilities. Its prevalence has increased around the world ever since. These international interests stimulated efforts to develop ways in which the discipline of conductive education (CE) could occur abroad and as a result, develop a worldwide network of practice. In the United States the first establishment of this international model of conductive education occurred in Grand Rapids, Michigan. Under the professional supervision of the András Petö Institute of Conductive Education and College for Conductor Training, (MPANNI in Hungarian), the Conductive Learning Center (CLC) was established in 1999, enrolling students to participate in the conductive education model and also serving as the laboratory school for the Aquinas College (AQ) teacher preparation program for earning the endorsement to teach the Physically and Otherwise Health Impaired (POHI). Currently, this collaborative program at AQ provided with MPANNI is unique in North America.
\end{abstract}

Key words: conductive education, András Pető, complex personality development, active learning, motor disability, conductor - teacher.

\section{The Brief History and Present of Conductive Education in Hungary}

$\mathrm{CE}$ is a holistic educational approach based on complex personality development. Its aim and, at the same time, its instrument is active learning built on intention and motivation, resulting in the overall development of the person living with motor disability.

The system of conductive education was developed in Hungary by András Petó, a physician and educator. He was the first person who did not consider a physical disability brought on by the central nervous system's injury a mere medical case, but a pedagogical and educational challenge. He viewed physical

Andrea Benyovszky, Conductive Learning Center, Aquinas College, Grand Rapids Michigan, USA; benyoand@ aquinas.edu 
disability as a cerebral coordination disorder which could be influenced by learning.

He acknowledged that people living with multiple disabilities due to the injury of the central nervous system often display a complex set of symptoms. The symptoms gradually change and as a result, the motor, social adaptation, cognitive and communication conditions shift in a positive or negative direction. The conditions last a lifetime and determine the quality of a person's life. The disability not only causes the loss or disorder of certain functions, but also their disintegration. The holistic approach of conductive education interprets personality as an integral whole and does not break it into parts but with the help of a complex conductive program, develops it consistently and organically. CE approaches the individual in an integral manner, which influences every area at the same time (Hári, 1997).

András Petö laid the foundation of the conductive pedagogical system in 1938. $\mathrm{He}$ elaborated and implemented his method for children living with motor disability in 1948. Following a successful two year experimental period, the Hungarian government officially established the National Institute for Movement Therapy in Budapest under Petö's directorship. After his death in 1967, the Institute was named after its founder. Today the András Petö Institute of Conductive Education and Conductor Training College is the center of the conductive educational network operating in various countries of the world.

The Institute is part of the Hungarian educational system and its activity focuses in three areas.

1. Training conductors in the conductors' College;

2. Providing conductive education for the motor disabled with damages to the central nervous system;

3. Conducting scientific research in the area of conductive education.

\section{The presence of conductive education in the United States}

The first studies on conductive education (CE), soon after the early stabilization period in Hungary (1940s and 1950s), reached Great Britain and Austria and with the transmission of translated material, the reputation of the Pető method arrived in the United States as well.

During the 1960s and to this day, a number of individuals have felt that studying conductive education as a possible alternative method in the treatment of the motor disabled would be valuable. This was, in part, due to the ineffectiveness of Cerebral Palsy (CP) therapies. There were many initiatives, mostly from parents of children with motor related disabilities, to launch and operate conductive groups in the U.S. In professional circles, information on conductive education began to spread in the 1990s when Mária Hári and her colleagues, 
invited by various American institutions and organizations, gave lectures on the subject. As a result, the July 1995 issue of "Infants and Young Children" was almost entirely dedicated to conductive education. A major transformation in the history of conductive education in America took place in 1999, when MPANNI's continuous professional presence began on the North American continent. This resulted in the launch of a conductive education teacher training program in the state of Michigan, which is based on the Hungarian curriculum and under the professional guidance of the Petö Institute.

\section{The conductive education teacher program at Aquinas College}

In 1991, The Dean of AQ requested that the Director of MPANNI participate in the development of a plan for a dual endorsement program that would provide students at AQ with both a Michigan teacher's endorsement for instruction for students with Physical or Otherwise Health Impaired needs and recognition as a conductive educator. A degree program to meet these objectives was created incorporating the theoretical and practice components of both the United States and Petó Institute perspectives. AQ financed the program and began the process of approval to provide the program at their site.

The goals of the collaboration between these higher education institutions were:

-to meet the desired need for conductive education within the United States

-to guarantee the maintenance of the integrity and fidelity of the conductive education method, and

-to expand the international network of MPANNI to North America.

The POHI/Conductive Education teacher preparation program at AQ introduced new elements to the traditional American special education teacher training model. The preparation program, based on the practices of MPANNI academic instructional practices, places special emphasis on the ongoing extensive application practice of students by working in a lab school setting. Laboratory school hours provide students with active learning opportunities, carefully structured to phase trainees into all aspects of teaching by gradually combining knowledge and responsibilities over time. Trainees have a minimum of 10 contact hours each week throughout their training, totaling 1050 hours prior to the student teaching placement. To provide the infrastructure for this application exercise to occur, the two institutions cooperated in establishing the Conductive Learning Center (CLC) to provide the laboratory experience.

The first class of conductive education began its studies in the 2001-2002 academic year at AQ as part of the POHI program. The curriculum included required laboratory hours of practice to be completed at the CLC. The overall curriculum consists of courses to address requirements for the certification in Michigan as an elementary general education teacher; those required for the 
endorsement as a teacher of the POHI, and the required content and practice related to the conductive education method and related biomedical courses. Upon graduation and the successful completion of state required assessments, students receive the following:

- a BA degree Elementary Education teacher certification (K-5, from preschool to grade 5)

- an endorsement to their teaching certificate to teacher special education/POHI grades K-12. and

- a conductor degree certificate.

\section{Conductive Learning Center}

The Conductive Learning Center (CLC) was established to provide the conductive education methodology for students with motor disabilities.

Originally, CE was brought to west Michigan by the efforts of parents of children with motor related disabilities in the summer of 1995. While two CE summer schools were organized by parents, they sought out AQ to take over the operation of the program in 1998. After AQ conductive education program was launched with the MPANNI and started, Aquinas appointed an independent board to operate the CLC as a financially independent arm of the college (2002). The college uses the CLC as a laboratory school for POHI student training. A strong sense of cooperation exits between the MPANNI, AQ and the CLC.

\section{Staffing:}

The staffing of the Conductive Learning Center is a combination of trained and certified Conductor teachers, professional staff and occasional volunteers.

The Executive Director of CLC is selected by the Board of Directors. She oversees the administrative aspects of the center and is not a certified conductorteacher.

The CLC Program Director is a Pető Institute certified and experienced Conductor Teacher and is appointed by the MPANNI. She directs, supervises the conductive education program, schedules and organizes students and conductors' placement.

The Conductor-teachers include AQ-Petô Institute certified conductor teachers who are resident Conductor teachers and Pető Institute assigned Conductor Teachers.

Between 1999 and 2005, the conductors delegated by MPANNI provided the instruction of the conductive education program for the participating students and families. (The conductive education model does not utilize the skills of the physical or occupational therapist, nor the employment of a speech pathologist. The model incorporates addressing these needs of the individual student). The conductor-teachers participated in the practical training of current AQ college 
POHI students with the guidance of the program director. Since 2006, graduates of the AQ POHI program and the conductors of MPANNI jointly provide conductive education duties.

Over the past 13 years, more than 60 Hungarian conductors have worked at CLC - for one to three four-week sessions with many returning on a rotating basis per their request and assignment.

The Media and Data Coordinator Prepares progress reports and student records, and creates database as needed. He creates digital photographic images and videos for student records and evaluation. He also collects and analyzes parent survey information. He is responsible for the creation of PowerPoint presentations about the program, as well as historical statistics and reports, for PR and visitor instruction. Finally, he assists with compiling pictures for the newsletter and special events.

Classroom assistants are conductor teachers in training and occasionally volunteers from the parents and community members.

Since becoming a financially independent arm of AQ, CLC has been working on strengthening and solidifying its financial base. CLC does not receive governmental funding for education, nor does it quality for payment by medical insurance. The primary base of funding is tuition, fundraising, grants and gifts. Much of the money that is donated to CLC comes from local sources that often stipulate that it be used to underwrite the cost of Michigan students.

\section{Families served by CLC}

The Conductive Learning Center serves children from birth to age 26 with motor disorders related to complications of prematurity, Cerebral Palsy, Spina Bifida or brain and spinal injury. Since its inception, the CLC has served more than 500 families. The program serves 70-80 students annually. Between 1999 and 2011, 306 children participated in a least one 4 week session.

The program attracts families not only from Michigan, but from other states as well as other countries. Frequently these families move to Grand Rapids for the period of time necessary to participate in the conductive education program. The distribution of the students by gender and state is shown in Chart 1. 


\begin{tabular}{|l|c|c|c|c|}
\hline & $\begin{array}{c}\text { MICHIGAN } \\
\text { STATE }\end{array}$ & $\begin{array}{c}\text { OTHER } \\
\text { STATE }\end{array}$ & $\begin{array}{c}\text { OTHER } \\
\text { COUNTRY }\end{array}$ & $\sum$ \\
\hline RECEIVED CE & 155 & 144 & 7 & 306 \\
\hline MALE & 100 & 83 & 3 & 186 \\
\hline FEMALE & 55 & 61 & 4 & 120 \\
\hline
\end{tabular}

Chart 1 Distribution of children according to their place of residence and gender (at time of application)

The CLC operates continuous conductive groups for local families during the traditional school calendar year and within the same school year offers a system of intervals of intensive sessions (4-5 weeks long). These sessions are frequently accessed by students and families that do not reside in close proximity to the CLC. There are nine school year sessions that are four weeks in length and additional summer sessions are five weeks long.

Both the amount of time of a session and placement of the child are flexible depending on the individual status of each child's ability to handle the length and level of instruction.

\section{Summary}

By its very existence and success, the CLC meets the needs of children living with disabilities for whom the traditional physical therapy approaches common in the United States have not worked. The program's success requires the fidelity of the CE model is ensured. The unique partnership of the Peto, AQ, and the CLC does just that.

The implementation of a conductive educational program which stays true to the Petö principles is not an impossible dream. Though the work has been intense and extremely complex, the impact on the lives of the students served makes it all worthwhile.

\section{References:}

BALOGH, E. and HÁRI, M. The place of conductive education in the rehabilitation of neurologic disorders. Pediatric Neurology, 1992, 5, 367-368.

BENYOVSZKY, A. Traditional and non-traditional cases in the conductive group: Admitting those who would benefit most from conductive education. In: Conductive Education/Occasional Papers, 2010. 
COTTON, E. The Institute for Movement Therapy and School for 'Conductors', Budapest, Hungary: a report of a study visit. Developmental Medicine and Child Neurology, 1965, 7, 437-446.

GAROFALO, V. J. Countries where conductive education has gained ground: USA. Conductive Education/Occasional Papers, 2005, 12, 63-80.

HÁRI, M. and ÁKOS, K. Conductive Education. Budapest: Tankönyvkiadó, 1971.

HÁRI M. The history of conductive education. Budapest: MPANNI, 1997.

HÁRI M. Comparative conductive education. Budapest: MPANNI, 1998.

HOUSE, J. B. Evaluating an Integrated Approach to the Management of Cerebral Palsy. Eau Claire: Wisconsin State University, 1971.

ILLYÉS S. ed. Basics of special education. Budapest: ELTE Gusztáv Bárczi College of Special Education, 2000.

KOZMA, I. and BALOGH, E. A brief introduction to conductive education and its application at an early age. Infants and Young Children, 1995, 1, 68-74.

+ MPANNI 